- 研究报告・

\title{
赛罕乌拉自然保护区蝶类多样性及其影响因素
}

\author{
洪雪萌 戈昕宇 李俊兰* \\ (内蒙古大学生命科学学院, 呼和浩特 010021)
}

摘要: 为了解赛罕乌拉自然保护区蝶类多样性及其影响因素, 我们于2017年5-9月分别对保护区的典型草原、湿 地、山地沟谷草甸、退化草原、农田、山地旱生灌从、山地中生灌丛等7种生境中的蝴蝶进行观测调查。共记录 和采集蝴蝶2,290只, 隶属5科42属63种。蛱蝶科的种类数(34种)和个体数(991只)最多。柑橘风蝶(Papilio xuthus)、 云粉蝶(Pontia daplidice)、绢粉蝶(Aporia crataegi)、兴麻蛱蝶(Aglais urticae)、银斑豹蛱蝶(Speyeria aglaja)等5种为 保护区的优势种。保护区蝶类群落的种-多度曲线呈正态分布模式, 表明保护区生态环境良好, 生境相互重叠, 蝶 类活动范围在不同生境中可以延伸。不同生境中蝶类群落种类及数量存在一定差异, 其中山地中生灌从蝶类群落 的多样性指数最高, 优势度指数最低; 退化草原的多样性指数和物种丰富度指数均为最低, 优势度指数最高; 山 地沟谷草甸的科、属、种、个体数最多; 退化草原的科、属、种、个体数都是最少。区系组成分析表明广布种占 $63.49 \%$, 古北种占 $36.51 \%$ 。保护区不同生境中蝶类群落多样性特征指数在各月份间有明显差异, 蝴蝶种类及个体 数与温度之间呈显著正相关, 与降雨量无显著相关性。综上, 我们认为适当的干扰有利于蝶类多样性发展, 而强烈 的人为干扰会严重破坏草场环境, 影响蝶类生存和繁衍, 降低蝶类多样性。

关键词: 蝴蝶; 多样性; 影响因素; 干扰; 赛罕乌拉自然保护区

\section{Butterfly diversity and its influencing factors in Saihanwula Nature Re- serve}

\author{
Xuemeng Hong, Xinyu Ge, Junlan $\mathrm{Li}^{*}$ \\ College of Life Sciences, Inner Mongolia University, Hohhot 010021
}

\begin{abstract}
To explore the factors explaining butterfly diversity in a landscape mosaic of different habitats, we conducted a series of field surveys in the Saihawla National Nature Reserve. This reserve comprised of seven habitats: typical grassland, wetland, mountain valley meadow, degraded grassland, farmland, mountain xerophytic shrub and mountainous shrub. From May to September 2017, we recorded a total of 2,290 butterfly individuals belonging to 63 species, 42 genera, and 5 families. Nymphalidae, with the most species (34) and the most individuals (991), was the dominant family in the reserve. Five species dominated the community: Papilio Xuthus, Pontia daplidice, Aporia crataegi, Aglais urticae, Speyeria aglaja. The species-abundance analysis showed a normal distribution model, suggesting a relatively stable community with the range of butterfly activity extending to different habitats due to the continuity of vegetation types. However, we also found that butterfly distribution in Saihanwula was closely related to the distribution and composition of vegetation among habitats. The Mountainous shrub had the highest biodiversity index and the lowest dominance index, whereas degraded grassland had the lowest biodiversity index and species richness, but the highest dominance index. The Mountain valley meadow had the most number of families, genera, species, and individuals, the degraded grassland had the lowest number of families, genera, species, and individuals. Faunal distribution analysis show that widely distributed species occupied $63.49 \%$ and Palaearctic species occupied $36.51 \%$. Furthermore, butterfly diversity in the different habitats of the reserve varied significantly between months. Finally, we found that numbers of butterfly individuals and species increased with higher temperatures, while rainfall had no significant correlation. In conclusion, We believe that appropriate interference is conducive to the development of butterfly diversity, strong human disturbance seriously destroyed
\end{abstract}

收稿日期: 2018-01-24; 接受日期: 2018-04-10 
grassland environment, affected butterfly survival and reproduction, and reduced butterfly diversity.

Key words: butterfly; diversity; influencing factors; interference; Saihanwula Nature Reserve

生物多样性是人及其他动植物赖以生存的物 质基础, 而昆虫多样性是生物多样性的重要组成部 分(梅杰等, 2015)。随着经济的快速发展, 生物栖息 地退化、碎片化以及环境污染问题日益突出。利用 昆虫种群与生境之间的关系, 选取有效的指示物种 来监测生境变化, 已成为生物多样性的研究热点, 对于维持生态平衡也至关重要。

蝴蝶属昆虫纲鳞翅目锤角亚目(李照广等, 2017), 因其个体较大、易于观察和鉴定、对寄主相 对专一(刘立伟等, 2015)、对栖息地环境质量要求较 高、能够快速响应生境特征的变化, 而且由于环境 变化导致其形态及生活史特征的变化易于对比, 从 而被选为环境质量、生境破碎化、生态恢复、气候 变化的可靠指示生物(张立微和张红玉, 2016; 谭灿 等, 2017)。早在20世纪50年代, 欧洲国家就已将蝶 类作为环境变化及优劣的指示物种, 对蝶类种类及 数量的观测调查已持续了 60 多年, 形成了较完整的 蝴蝶监测体系(房丽君等, 2013)。我国关于蝶类的调 查仍处于起步阶段, 大多数保护区内开展的蝶类多 样性调查研究主要集中在蝴蝶种类及群落结构方 面(吴雨恒等，2016), 如：李密(2011)、梅杰等 (2015)、翁锦汭等(2017)。但这些调查时间短、调查 区域小、数据链不完整, 蝴蝶多样性应进行长时间、 大范围、定期、定点的动态观测。

内蒙古位于中国北疆, 偏远辽阔, 对蝶类的研 究报道极少, 仅有的几篇报道也只是停留在初步的 种类调查阶段, 对蝶类多样性及其结构和功能、区 系分析、影响因素等均无介绍。2016年环境保护部 设立了全国蝶类生物多样性保护项目, 本单位申请 赛罕乌拉作为观察点, 对蝶类多样性及群落变化进 行长期定点动态监测, 以期对保护区蝴蝶资源保 护、生态系统健康评价、生物多样性保护提供基础 资料。

\section{研究方法}

1.1 观测地点

赛罕乌拉国家级自然保护区位于内蒙古自治 区赤峰市巴林右旗北部, 地处大兴安岭南段山地。
地理坐标为 $118^{\circ} 18^{\prime}-118^{\circ} 55^{\prime} \mathrm{E}, 43^{\circ} 59^{\prime}-44^{\circ} 27^{\prime} \mathrm{N}$, 平 均海拔850-1,850 m, 总面积100,400 $\mathrm{km}^{2}$ (陈乐等, 2013)。保护区属中温带半湿润温寒气候区，冬季寒 冷漫长、降雪量少, 夏季炎热短促、昼夜温差大, 秋 季气温下降快, 年平均气温 $2^{\circ} \mathrm{C}$, 最高气温 $29^{\circ} \mathrm{C}$, 最 低气温 $-32^{\circ} \mathrm{C}$, 无霜期在 $100 \mathrm{~d}$ 左右(陈乐等, 2013)。 年均降水量约 $400 \mathrm{~mm}$, 主要集中在6-8月(哈琴等, 2013; 贾晓燕等, 2014)。该区属森林草原交错带，植 被以森林为主, 主要树种为山杨(Populus davidiana)、白华(Betula platyphylla)、蒙古柇(Quercus mongolica)、天然华北落叶松(Larix pricepis-ruprechtii)、虎榛子(Ostryopsis davidiana)、山杏 (Prunus sibirica)等。草原、草甸、河流也有较大范围分布(张 书理等, 2008)。

在保护区内选择典型草原、湿地、山地沟谷草 甸、退化草原、农田、山地旱生灌从、山地中生灌 丛等7种生境, 每种生境设置1条样线(图1), 每条样 线长 $2 \mathrm{~km}$, 各划分为 10 个样段, 每样段长 $200 \mathrm{~m}$ 。按 照中华人民共和国国家环境保护标准HJ710.9-2014 将干扰强度分为: (1)强: 生境受到严重干扰, 植被 基本消失，野生动物难以栖息繁衍。(2)中: 生境受 到干扰，植被部分消失，但在干扰停止或消失后， 植被仍可恢复。(3)弱: 生境受到一定干扰，植被基本 保持自然生长状态, 对野生动物栖息繁衍影响不大。 (4)无：生境没有受到干扰，植被保持原始状态，对 野生动物栖息繁衍没有影响。各生境详细情况如下:

(1)典型草原: 位于实验区, 海拔1,030-1,033.5 m。 植被主要为多年生旱生草本植物，以禾本科、豆科、 菊科植物为主, 伴生有小半灌木。5月中下旬, 早春 植物如细叶白头翁(Pulsatilla turczaninovii)、马萄草 (Iris ensata)、狼毒花(Stellera chamaejasme)等相继开 花; 6月中下旬, 气温升高, 大多数植物及针茅类展 开新叶, 大麻(Cannabis sativa)、黄芩(Scutellaria baicalensis)等竞相开放; 7月, 在降水及温度适宜的 条件下, 禾本科及草本植物最为茂盛, 夹杂着紫苜 宿(Medicago sativa)、鞭挞狗娃花(Heteropappus tataricus)、草木犀(Melilotus officinalis)等。8月中下 旬进入牧民剪草的大忙时节, 有中度人为干扰, 直 


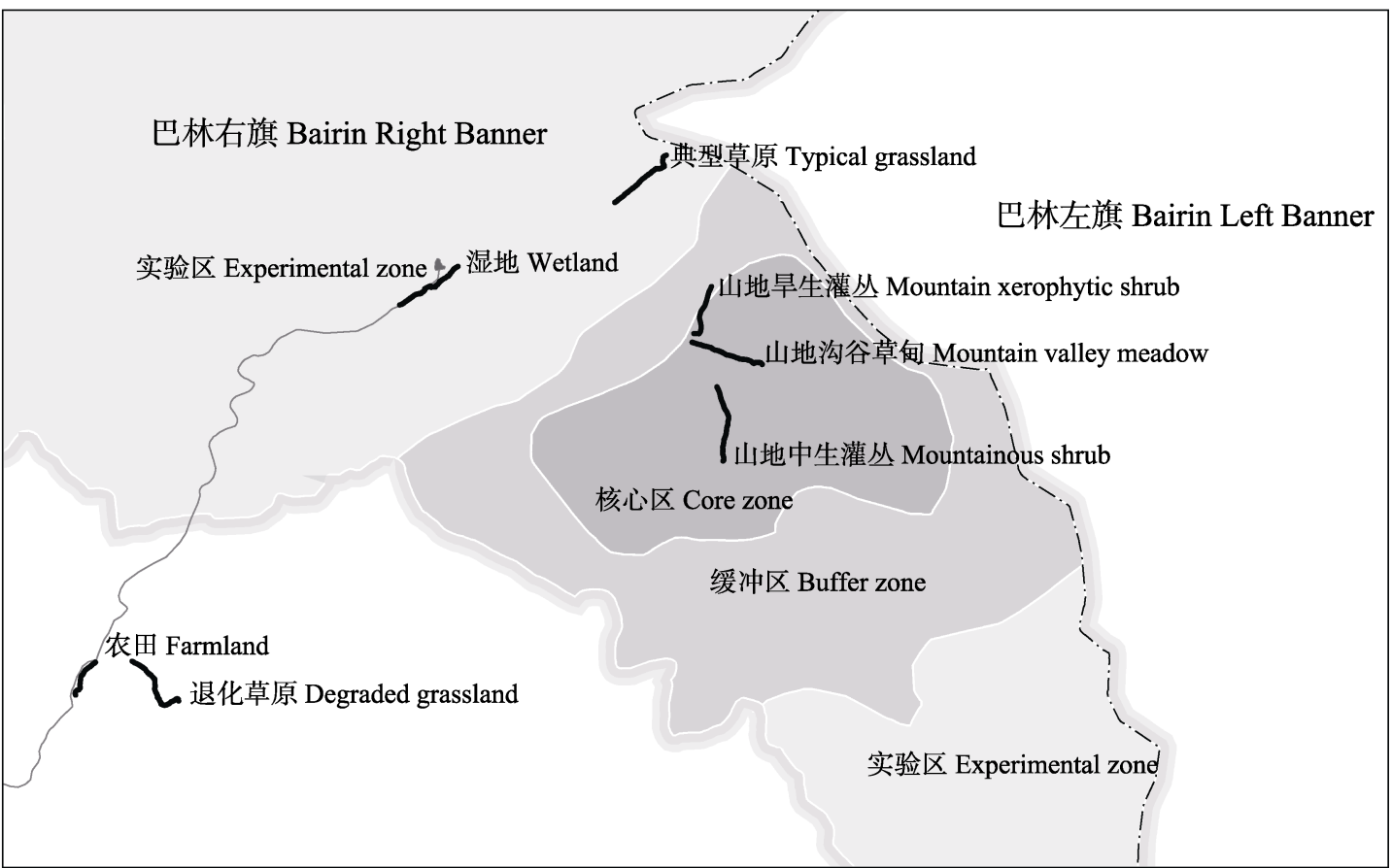

图1 赛罕乌拉自然保护区蝴蝶调查样线分布情况

Fig. 1 Distribution of the survey line of butterfly in Saihanwula Nature Reserves (black line)

到9月植物完成生长周期前被全部割掉。

(2)湿地：位于实验区, 海拔971.25-972.2 m。植 被主要为半灌木及多年生草本植物, 以菊科冷蒿 (Artemisia frigida)、禾本科狗尾草(Setaria viridis)及 节节麦(Aegilops tauschii)为主，还有玉米等农作物。 靠近居民区, 有鸡鸭鹅马牛羊等家禽和牲畜活动, 也有居民的耕作活动, 为中度干扰。8月强降雨引起 水涝灾害, 样线被破坏。

(3)山地沟谷草甸：位于核心区, 海拔1,093.5$1,129.75 \mathrm{~m}$ 。主要为灌木与草本植物, 伴生有落叶乔 木, 植被生长茂盛。5月蓄薇科稠李(Prunus padus)、 海棠花(Malus spectabilis) 等生长茂盛, 开白色花 朵。6月气温升高, 榆树(Ulmus pumila)、桦对 (Betula ermanii)等新叶相继展开, 草本植物茂密。7-8月为 生长茂盛期, 灌木、乔木等交错生长。9 月气温降低, 进入秋季, 花朵及叶片调落。此生境仅有高校及研 究所定期进行观测调查, 干扰为弱。

(4)退化草原：位于保护区外, 海拔 913.75$914 \mathrm{~m}$, 地表半裸露至裸露, 草场退化, 仅有小叶锦 鸡儿(Caragana microphylla)一种植物, 少有杂草覆 盖。因过度放牧, 草场荒漠化, 有强烈人为干扰。

(5)农田: 位于保护区外, 海拔875-881.75 m,
是林农交错带, 靠近河流, 以人工林为主, 杨柳科、 松科等植物丰富, 伴生有高大禾草芦苇(Phragmites australis)等。此处土壤为沙土, 土壤凝聚力差, 靠近 河流, 土壤流失严重, 主要受中度居民耕作及放牧 干扰。

(6)山地旱生灌从: 位于缓冲区与核心区边界, 海拔1,104.25-1,189.25 m, 在山坡坡体上, 灌木及 草本植物茂密, 主要为山杏灌从及禾本科杂草, 伴 生少数乔木。人为干扰程度弱, 只有高校及研究所 的观测行为。

(7)山地中生灌丛: 位于核心区, 海拔1,139.75$1,203.25 \mathrm{~m}$, 常见高大乔木, 天然华北落叶松、白 桦、白杨(Populus tomentosa)等生长茂盛, 稠李、海 棠花等灌木与草本植物也茂密排布, 这里气候湿润, 几乎无人为干扰。

\section{2 观测时间和方法}

野外调查于2017年5-9月进行, 每隔20天调查1 次。选择晴朗无大风的天气, 强风或雨天顺延, 调 查时间选择蝶类活动频繁的10:00-16:00。调查采用 Poolard路线样带法, 从起点开始使用GPS进行线路 追踪, 并在每个样段起始点进行打点标识。以1.5$2 \mathrm{~km} / \mathrm{h}$ 的速度徒步观测记录或网捕样线两边宽 
$2.5 \mathrm{~m}$ 、由地面向上 $5 \mathrm{~m}$ 范围内的蝴蝶。将采集到的 蝴蝶掐胸部致死后装入硫酸纸制成的三角袋内, 记 录采集时间、地点、采集人、样线、样段等信息，带 回实验室制成标本、分类统计, 物种鉴定参照《中 国蝴蝶分类与鉴定》和《中国蝶类志》(周尧, 1994, 1998)。

\section{3 数据处理}

通过Google Earth定位系统对观测轨迹进行位 点校对, KML格式导出。群落多样性的衡量参数包 括物种数、Shannon-Wiener多样性指数 $\left(H^{\prime}\right)$; Margalef物种丰富度指数 $(R)$ 、Simpson优势度指数 $(D)$ 、 Pielou均匀度指数 $(J)$ 等(李佳琳等, 2011; 顾伟等, 2015; 周光益等, 2016), 各指数计算公式如下:

$$
\begin{aligned}
& H^{\prime}=-\sum_{i=1}^{S}\left(P_{i} \operatorname{Ln} P_{i}\right) ; \quad P_{i}=N_{i} / N \\
& R=(S-1) / \ln N \\
& D=\sum_{i=1}^{S}\left(P_{i}\right)^{2} \\
& J=H^{\prime} / \operatorname{Ln} S
\end{aligned}
$$

式中, $S$ 为调查区内蝶类的种数, $P_{i}$ 为第 $\mathrm{i}$ 种的个体数 占总个体数的比例, $N$ 为所有种的个体总数, $N_{i}$ 为种 $i$ 的个体数。

定义个体数所占比例超过所在生境个体总数 $5 \%$ 以上的为优势种, 1-5\%的为常见种, $0.5-1 \%$ 的为 少见种, 不足 $0.5 \%$ 的为稀有种。

根据本实验所得蝴蝶种类及个体数情况, 选 $\log _{3}$ 作为标尺, 在 $X$ 轴为 $\log _{3}$ 标尺的倍程刻度(即 1 , 2-4, 5-13, 14-40, 40-121..... 各个倍程), $Y$ 为普通算 术刻度的半对数直角坐标系中, 以蝴蝶个体数为横 坐标，种类数为纵坐标绘制种-多度曲线。

利用Office Excel 2010和SPSS 18软件对数据进 行多样性及Pearson相关性分析。降水及气温数据由 内蒙古赤峰市巴林右旗气象局提供。

\section{2 结果}

\section{1 赛罕乌拉保护区蝶类群落组成及区系特征}

共采集和记录蝴蝶 63 种 2,290 只, 隶属于 5 科 42 属(表1)。从科级组成上看, 蛱蝶科的属、种及个体 数最多, 共计 21 属 34 种 991 只, 占总种类数的 $53.97 \%$, 总个体数的 $43.28 \%$, 为保护区的科级优势
类群; 粉蝶科个体数 (765只)仅次于蛱蝶科, 占总个 体数的 $33.40 \%$, 但种类较少, 只有 6 属 10 种; 凤蝶 科、灰蝶科的属、种及个体数较少, 共占个体总数 的 $22.45 \%$; 弄蝶科的种类数和个体数最少, 仅占个 体总数的 $0.8 \%$, 为科级水平的稀有类群。从属级组 成上看, 蝶类群落以单种属为主, 共有 27 属, 占总 属数的 $64.29 \%$, 其余 15 属为多种属, 占总属数的 $35.71 \%$ 。不同生境的优势类群有所差异，但粉蝶属、 环蛱蝶属、蛱蝶属等仍为主要属, 是保护区优势类 群。从种级组成上看，优势种 5 种，即，柑橘凤蝶 (Papilio xuthus)、云粉蝶 (Pontia edusa)、绢粉蝶 (Aporia crataegi)、菖麻蛱蝶(Aglais urticae)、银斑豹 蛱蝶(Speyeria aglaja)。常见种19种, 其余为少见种 和稀有种。区系组成分析表明：广布种 40 种，占 $63.49 \%$; 古北种 23 种，占36.51\% (表1)。

不同生境中蝶类群落种类及数量存在一定差 异。有微弱干扰的山地沟谷草甸有 49 种 973 只, 其中 柑橘风蝶、菖麻蛱蝶、绢粉蝶、银斑豹蛱蝶、单环 蛱蝶(Neptis rivularis)的数量较多, 共占此生境总个 体数的 $51.18 \%$, 为山地沟谷草甸的优势种; 折线蛱 蝶(Limenitis sydyi)、朱蛱蝶(Nymphalis xanthomelas)、黎戈灰蝶(Glaucopsyche lycormas)等14种蝶类 的个体数占此生境总数的 $1-5 \%$, 为常见种; 小豹蛱 蝶(Brenthis daphne)、红线蛱蝶(Limenitis populi)等12 种为少见种, 斑缘豆粉蝶(Colias erate)等18种为稀 有种。凤蝶科虽仅有 2 属 3 种, 但柑橘凤蝶的个体数 量极多, 为此生境的优势类群, 表现出强烈的适应 性。无人为干扰的山地中生灌从有 45 种 503 只, 绢粉 蝶、柑橘凤蝶、单环蛱蝶、折线蛱蝶、银斑豹蛱蝶、 白矩朱蛱蝶 (Nymphalis vau-album)的数量较多, 共 占此生境个体总数的 $52.08 \%$, 为山地中生灌从的优 势种, 尖钩粉蝶(Gonepteryx mahaguru)、红线蛱蝶、 朱蛱蝶等17种为常见种，菖麻蛱蝶、花弄蝶(Pyrgus maculatus)、大网蛱蝶(Melitaea scotosia)等13种为少 见种，其余 9 种为稀有种。此生境中凤蝶科和粉蝶科 个体数多, 蛱蝶科的种类较多。中度人为干扰的湿 地有18种290只, 云粉蝶、菖麻蛱蝶、斑缘豆粉蝶、 菜粉蝶(Pieris rapae)共占个体总数的 $80.34 \%$, 为此 生境的优势种，其中云粉蝶一种就占56.21\%，表现 出对此生境强烈的适应性。绢粉蝶、柑橘凤蝶等7 种为常见种, 小豹蛱蝶、县梦灰蝶(Thersamonia 
表1 赛罕乌拉国家级自然保护区不同生境的蝴蝶种类与数量

Table 1 Species and individual number of butterflies in different habitats in Saihanwula National Nature Reserve

\begin{tabular}{|c|c|c|c|c|c|c|c|c|c|c|c|}
\hline \multirow{2}{*}{$\begin{array}{l}\text { 科 } \\
\text { Family }\end{array}$} & \multirow{2}{*}{$\begin{array}{l}\text { 属 } \\
\text { Genus }\end{array}$} & \multirow{2}{*}{$\begin{array}{l}\text { 种 } \\
\text { Species }\end{array}$} & \multicolumn{7}{|c|}{ 生境 Habitat type } & \multirow{2}{*}{$\begin{array}{l}\text { 总计 } \\
\text { Total }\end{array}$} & \multirow{2}{*}{$\begin{array}{l}\text { 区系成分 } \\
\text { Fauna } \\
\text { composition }\end{array}$} \\
\hline & & & I & II & III & IV & $\mathrm{V}$ & VI & VII & & \\
\hline \multirow{3}{*}{$\begin{array}{l}\text { 凤蝶科 } \\
\text { Papilionidae }\end{array}$} & 凤蝶属 Papilio & 金凤蝶 Papilio machaon & 3 & & 7 & & 1 & & & 11 & $\mathrm{~W}$ \\
\hline & & 柑橘凤蝶 Papilio xuthus & 2 & 9 & 222 & & 2 & 23 & 58 & 316 & $\mathrm{~W}$ \\
\hline & 绢蝶属 Parnassius & 小红珠绢蝶 Parnassius nomion & & & 4 & & & & 4 & 8 & $\mathrm{~W}$ \\
\hline \multirow{10}{*}{$\begin{array}{l}\text { 粉蝶科 } \\
\text { Pieridae }\end{array}$} & 绢粉蝶属 Aporia & 绢粉蝶 Aporia crataegi & 8 & 14 & 67 & 1 & & 84 & 63 & 237 & $\mathrm{~W}$ \\
\hline & & 小檗绢粉蝶 Aporia hippia & & & 22 & & & & 6 & 28 & $\mathrm{~W}$ \\
\hline & 云粉蝶属 Pontia & 云粉蝶 Pontia edusa & 73 & 163 & 18 & 6 & 19 & 13 & 12 & 304 & $\mathrm{~W}$ \\
\hline & 粉蝶属 Pieris & 菜粉蝶 Pieris rapae & 11 & 19 & 9 & & 4 & 6 & 10 & 59 & $\mathrm{~W}$ \\
\hline & 小粉蝶属 Leptidea & 突角小粉蝶 Leptidea amurensis & 1 & & 25 & & & 4 & 6 & 36 & $\mathrm{P}$ \\
\hline & 钩粉蝶属 Gonepteryx & 尖钩粉蝶 Gonepteryx mahaguru & & & 2 & & & & 19 & 21 & $\mathrm{~W}$ \\
\hline & 豆粉蝶属 Colias & 斑缘豆粉蝶 Colias erate & 2 & 20 & 4 & & 35 & & 2 & 63 & $\mathrm{~W}$ \\
\hline & & 黑缘豆粉蝶 Colias palaeno & & & & & & & 1 & 1 & $\mathrm{P}$ \\
\hline & & 镏金豆粉蝶 Colias chrysotheme & & & 8 & & & 3 & & 11 & $\mathrm{P}$ \\
\hline & & 橙黄豆粉蝶 Colias fieldii & & & & & & & 5 & 5 & $\mathrm{~W}$ \\
\hline \multirow{29}{*}{$\begin{array}{l}\text { 蛱蝶科 } \\
\text { Nymphalidae }\end{array}$} & 环蛱蝶属 Neptis & 单环蛱蝶 Neptis rivularis & & & 52 & & & 15 & 41 & 108 & $\mathrm{~W}$ \\
\hline & & 重环蛱蝶 Neptis alwina & & & 25 & & & 8 & 11 & 44 & $\mathrm{~W}$ \\
\hline & & 黄环蛱蝶 Neptis themis & & & 1 & & & 1 & 8 & 10 & $\mathrm{~W}$ \\
\hline & 线蛱蝶属 Limenitis & 折线蛱蝶 Limenitis sydyi & 2 & & 46 & & & 12 & 40 & 100 & $\mathrm{~W}$ \\
\hline & & 红线蛱蝶 Limenitis populi & & & 8 & & & & 16 & 24 & $\mathrm{~W}$ \\
\hline & & 扬眉线蛱蝶 Limenitis helmanni & & & 19 & & & & 17 & 36 & $\mathrm{~W}$ \\
\hline & & 戟眉线蛱蝶 Limenitis homeyeri & & & 1 & & & & & 1 & $\mathrm{P}$ \\
\hline & 闪蛱蝶属 Apatura & 柳紫闪蛱蝶 Apatura iris & & 3 & 2 & & & & 16 & 21 & $\mathrm{~W}$ \\
\hline & & 夜迷蛱蝶 Mimathyma nycteis & & 2 & 9 & & & 7 & 1 & 19 & $\mathrm{P}$ \\
\hline & 云蛱蝶属 Brenthis & 小豹蛱蝶 Brenthis daphne & 1 & 2 & 9 & 3 & & 8 & 5 & 28 & $\mathrm{~W}$ \\
\hline & 网蛱蝶属 Melitaea & 大网蛱蝶 Melitaea scotosia & 3 & 1 & 5 & & & & 3 & 12 & $\mathrm{P}$ \\
\hline & & 帝网蛱蝶 Melitaea diamina & & & & & & 8 & & 8 & $\mathrm{P}$ \\
\hline & 红蛱蝶属 Vanessa & 小红蛱蝶 Vanessa cardui & & 3 & 1 & & & 2 & & 6 & $\mathrm{~W}$ \\
\hline & & 大红蛱蝶 Vanessa indica & 2 & 6 & & & & 1 & & 9 & $\mathrm{~W}$ \\
\hline & 钩蛱蝶属 Polygonia & 白钩蛱蝶 Polygonia calbum & & & 3 & & & & & 3 & $\mathrm{~W}$ \\
\hline & & 黄钩蛱蝶 Polygonia c-aureum & & & & & & & 1 & 1 & $\mathrm{~W}$ \\
\hline & 麻蛱蝶属 Aglais & 苦麻蛱蝶 Aglais urticae & 10 & 31 & 95 & & 3 & 2 & 5 & 146 & $\mathrm{~W}$ \\
\hline & 蛱蝶属 Nymphalis & 白矩朱蛱蝶 Nymphalis vau-album & & & 37 & & & 6 & 26 & 69 & $\mathrm{~W}$ \\
\hline & & 朱蛱蝶 Nymphalis xanthomelas & & 6 & 43 & & & & 10 & 59 & $\mathrm{~W}$ \\
\hline & 蜜蛱蝶属 Mellicta & 网纹蜜蛱蝶 Mellicta dictynna & & & 12 & & & & 6 & 18 & $\mathrm{P}$ \\
\hline & 斑豹䊿蝶属 Speyeria & 银斑豹蛱蝶 Speyeria aglaja & 5 & & 62 & & & 13 & 34 & 114 & $\mathrm{P}$ \\
\hline & & 灿福蛱蝶 Fabriciana adippe & & 1 & 20 & 1 & & 1 & 5 & 28 & $\mathrm{~W}$ \\
\hline & 豹蛱蝶属 Argynnis & 绿豹蛱蝶 Argynnis paphia & & & 17 & & & 9 & 1 & 27 & $\mathrm{~W}$ \\
\hline & 斐豹蛱蝶属 Argyronome & 老豹蛱蝶 Argyronome laodice & & & 9 & & & & & 9 & $\mathrm{~W}$ \\
\hline & 链眼蝶属 Lopinga & 黄环链眼蝶 Lopinga achine & & & 4 & & & & & 4 & $\mathrm{P}$ \\
\hline & 珍眼蝶属 Coenonympha & 爱珍眼蝶 Coenonympha oedippus & & & 6 & & & 16 & 5 & 27 & $\mathrm{~W}$ \\
\hline & & 英雄珍眼蝶 Coenonympha hero & & & 3 & & & & 7 & 10 & $\mathrm{~W}$ \\
\hline & & 牧女珍眼蝶 Coenonympha amaryllis & & & & & & 3 & & 3 & $\mathrm{~W}$ \\
\hline & 炫黑眼蝶属 Atercoloratus & 炫黑眼蝶 Atercoloratus alini & & & 5 & & 1 & & & 6 & $\mathrm{P}$ \\
\hline
\end{tabular}


表1 (续) Table 1 (continued)

\begin{tabular}{|c|c|c|c|c|c|c|c|c|c|c|c|}
\hline \multirow{2}{*}{$\begin{array}{l}\text { 科 } \\
\text { Family }\end{array}$} & \multirow{2}{*}{$\begin{array}{l}\text { 属 } \\
\text { Genus }\end{array}$} & \multirow{2}{*}{$\begin{array}{l}\text { 种 } \\
\text { Species }\end{array}$} & \multicolumn{7}{|c|}{ 生境 Habitat type } & \multirow{2}{*}{$\begin{array}{l}\text { 总计 } \\
\text { Total }\end{array}$} & \multirow{2}{*}{$\begin{array}{l}\text { 区系成分 } \\
\text { Fauna } \\
\text { composition }\end{array}$} \\
\hline & & & I & II & III & IV & $\mathrm{V}$ & VI & VII & & \\
\hline & 阿芬眼蝶属 Aphantopus & 阿芬眼蝶 Aphantopus hyperantus & & & & & & & 3 & 3 & $\mathrm{P}$ \\
\hline & 多眼蝶属 Kirinia & 多眼蝶 Kirinia epaminondas & & & 11 & & & 4 & 8 & 23 & $\mathrm{~W}$ \\
\hline & 蛇眼蝶属 Minois & 蛇眼蝶 Minois dryas & & 1 & 7 & & & 2 & 3 & 13 & $\mathrm{~W}$ \\
\hline & 蟾眼蝶属 Triphysa & 蟾眼蝶 Triphysa phryne & 1 & & & & & & & 1 & $\mathrm{P}$ \\
\hline & 白眼蝶属 Melanargia & 白眼蝶 Melanargia halimede & & & 1 & & & & & 1 & $\mathrm{P}$ \\
\hline \multirow{13}{*}{$\begin{array}{l}\text { 灰蝶科 } \\
\text { Lycaenidae }\end{array}$} & 新灰蝶属 Neolycaena & 白斑新灰蝶 Neolycaena tengstroemi & & & & 33 & & & 1 & 34 & $\mathrm{~W}$ \\
\hline & 眼灰蝶属 Polyommatus & 多眼灰蝶 Polyommatus erotides & & & 1 & & & & & 1 & $\mathrm{P}$ \\
\hline & 爱灰蝶属 Aricia & 中华爱灰蝶 Aricia mandschurica & 4 & & 2 & & 1 & 4 & & 11 & $\mathrm{P}$ \\
\hline & 红珠灰蝶属 Lycaeides & 红珠灰蝶 Lycaeides argyrognomon & 1 & 2 & 1 & 2 & 4 & 1 & 4 & 15 & $\mathrm{P}$ \\
\hline & & 青海红珠灰蝶 Lycaeides qinghaiensis & & & 1 & 4 & & 2 & 1 & 8 & $\mathrm{P}$ \\
\hline & 琉璃灰蝶属 Celastrina & 琉璃灰蝶 Celastrina argiolus & & 5 & & & 1 & 1 & & 7 & $\mathrm{~W}$ \\
\hline & 蓝灰蝶属 Everes & 蓝灰蝶 Everes argiades & 2 & & 18 & & & 5 & 6 & 31 & $\mathrm{~W}$ \\
\hline & 线灰蝶属 Thecla & 线灰蝶 Thecla betulae & & & 1 & & & 3 & 1 & 5 & $\mathrm{~W}$ \\
\hline & 灰蝶属 Lycaena & 斑貉灰蝶 Lycaena virgaureae & & & 5 & & & & 6 & 11 & $\mathrm{P}$ \\
\hline & & 县梦灰蝶 Thersamonia thersamon & & 2 & & & & & & 2 & $\mathrm{P}$ \\
\hline & 豆灰蝶属 Plebejus & 豆灰蝶 Plebejus argus & 1 & & & & & & & 1 & $\mathrm{~W}$ \\
\hline & 戈灰蝶属 Glaucopsyche & 黎戈灰蝶 Glaucopsyche lycormas & & & 40 & & & 3 & 5 & 48 & $\mathrm{P}$ \\
\hline & 酒灰蝶属 Satyrium & 刺疬酒灰蝶 Satyrium spini & & & 1 & & & & 4 & 5 & $\mathrm{P}$ \\
\hline \multirow{3}{*}{$\begin{array}{l}\text { 弄蝶科 } \\
\text { Hesperiidae }\end{array}$} & 链弄蝶属 Heteropterus & 链弄蝶 Heteropterus morpheus & & & & & & & 1 & 1 & $\mathrm{P}$ \\
\hline & 花弄蝶属 Pyrgus & 花弄蝶 Pyrgus maculatus & 1 & & 2 & & & & 4 & 7 & $\mathrm{~W}$ \\
\hline & & 北方花弄蝶 Pyrgus alveus & & & & & & & 12 & 12 & $\mathrm{~W}$ \\
\hline 总计 Total & & & 133 & 290 & 973 & 50 & 71 & 270 & 503 & 2,290 & \\
\hline
\end{tabular}

I: 典型草原; II: 湿地; III: 山地沟谷草甸; IV: 退化草原; V: 农田; VI: 山地旱生灌丛; VII: 山地中生灌丛。P: 古北种; W: 广布种 I, Typical grassland; II, Wetland; III, Mountain valley meadow; IV, Degraded grassland; V, Farmland; VI, Mountain xerophytic shrub; VII, Mountainous shrub. P, Palaearctic species; W, Widely distributed species

thersamon)等4种为少见种, 大网蛱蝶等 3 种为稀有 种。山地旱生灌从有弱的人为干扰，共有31种 270 只, 绢粉蝶、柑橘凤蝶、爱珍眼蝶(Coenonympha oedippus)、单环蛱蝶为优势种，占个体总数的 $51.1 \%$, 云粉蝶、折线蛱蝶等 18 种为常见种, 小红蛱蝶 (Vanessa cardui)等4种为少见种, 其余5种为稀有种, 此生境蛱蝶种类数较多, 但个体数很少。有剪草等 中度人为干扰的典型草原共有19种133只，优势种 为云粉蝶、菜粉蝶、菖麻蛱蝶、绢粉蝶, 占总个体 数的 $76.69 \%$, 银斑豹蛱蝶、中华爱灰蝶 (Aricia mandschurica) 等 9 种为常见种, 共占个体总数的 $18.80 \%$, 其余为少见种, 无稀有种。农田主要受耕 作及放牧的中度干扰, 共有 10 种 71 只, 优势种为斑 缘豆粉蝶、云粉蝶、红珠灰蝶 (Lycaeides argyrognomon)和菜粉蝶, 共占个体总数的 $87.32 \%$, 常 见种为荨麻蛱蝶、柑橘凤蝶等6种。在湿地、山地
旱生灌从、典型草原中粉蝶科的不同种都表现出较 强的适应性, 是保护区内的优势类群。受强烈干扰 的退化草原有 7 种 50 只, 仅白斑新灰蝶 (Neolycaena tengstroemi)占个体总数的 $66 \%$, 为优势种, 其余6种 为常见种。

\section{2 不同生境蝶类群落种一多度分析}

保护区蝶类群落的种-多度曲线(图2)呈现正态 分布，处于第4-5倍程的个体数量较大的优势种和 处于第 1 倍程的个体数仅为 1 的稀有种在群落中只 占少数, 绝大多数物种数量居中。不同生境蝶类群 落种-多度曲线的分析结果表明(图3): 山地沟谷草 甸、山地旱生灌从、山地中生灌从蝶类呈现出对数 正态分布模式, 其中山地中生灌从的拟合效果最好, 山地沟谷草甸、山地旱生灌丛次之。稀有种和优势 种较少，而处于中间的常见物种很多，大多数蝶类 都表现出了较高的适应性; 湿地生境为不典型的对 


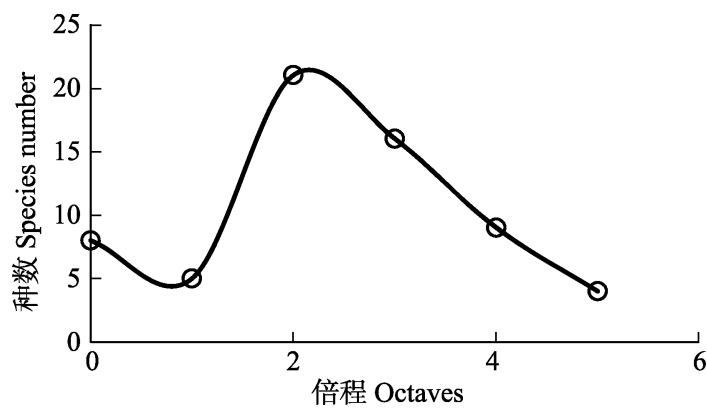

图2 赛罕乌拉保护区蝶类群落种-多度曲线

Fig. 2 Species-abundance curve for the butterflies in Saihanwula Nature Reserve

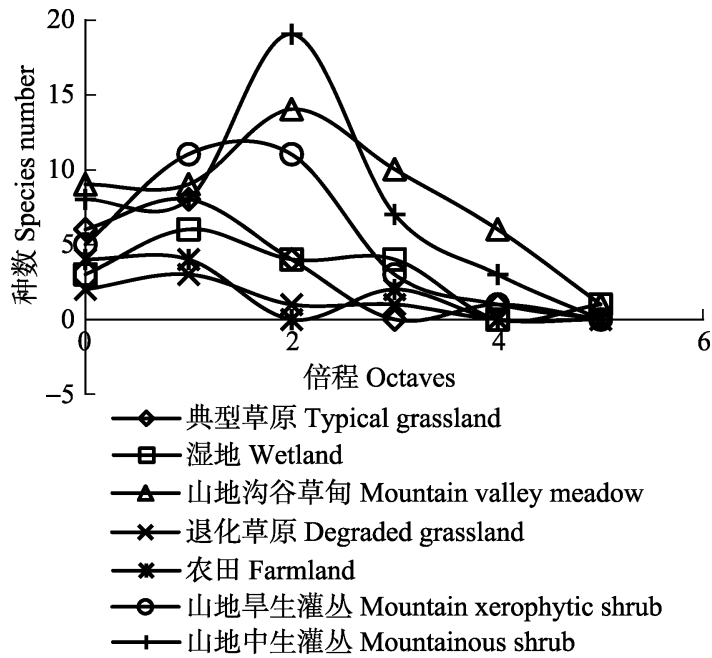

图3 不同生境蝶类群落种-多度曲线

Fig. 3 Species-abundance curves for butterfly in different habitats

数正态分布模式, 优势种少, 稀有种和常见种有增 多趋势。典型草原、退化草原、农田生境都表现为
对数级数模型, 符合生态位优先占领假说, 即群落 中物种对资源的占有表现为逐级占领趋势。典型草 原中常见种和优势种极少，主要集中在少见种; 退 化草原、农田生境均表现出稀有种较多而常见种很 少的特征。

\section{3 不同生境蝶类群落多样性}

不同生境蝶类群落多样性差异显著：无人为干 扰的山地中生灌从的多样性指数、丰富度指数和均 匀度指数最高, 优势度指数最低; 有适宜人为干扰 的山地沟谷草甸中蝴蝶的科、属、种以及个体数均 最高, 且多样性指数、丰富度指数仅次于山地中生 灌从; 受到强烈干扰的退化草原蝴蝶的多样性指数 和丰富度指数最低, 优势度指数最高, 且蝴蝶的 科、属、种以及个体数均最少, 但均匀度指数湿地 最低, 退化草原较湿地略高(表2)。

\section{4 不同生境蝶类群落多样性的时序动态}

不同生境中蝶类群落多样性指数在各月份间 有明显差异(图4)。各生境5-6月均逐渐升高，其中山 地旱生灌从、山地中生灌丛在7月达到最大值，其余 生境在6月达到最大值, 这与6-7月温度升高蝶类羽 化进入高峰期、寄主植物最为繁茂适合蝶类生存和 繁衍密切相关。8月各生境多样性指数均逐渐下降, 但湿地、山地沟谷草甸、退化草原、农田生境在8-9 月还有一定的波动。

各生境均匀度指数总体上较平稳, 只有退化草 原生境波动较大，在7月和9月分别出现两个高峰。 典型草原在5-7月较平稳，之后随时间的推移逐渐

表2 不同生境蝴蝶群落的多样性指数

Table 2 Diversity indicies of butterfly community in different habitats

\begin{tabular}{lllllllll}
\hline $\begin{array}{l}\text { 生境 } \\
\text { Habitat type }\end{array}$ & $\begin{array}{l}\text { 科数 } \\
\text { Family }\end{array}$ & $\begin{array}{l}\text { 属数 } \\
\text { Genera }\end{array}$ & $\begin{array}{l}\text { 种数 } \\
\text { Number of } \\
\text { species }\end{array}$ & $\begin{array}{l}\text { 个体数 } \\
\text { Individual } \\
\text { number }\end{array}$ & $\begin{array}{l}\text { 多样性指数 } \\
\text { Diversity index } \\
\left(H^{\prime}\right)\end{array}$ & $\begin{array}{l}\text { 均匀度指数 } \\
\text { Evenness index } \\
(J)\end{array}$ & $\begin{array}{l}\text { 优势度指数 } \\
\text { Dominance index } \\
(D)\end{array}$ & $\begin{array}{l}\text { 物种丰富度指数 } \\
\text { Species richness } \\
\text { index }(R)\end{array}$ \\
\hline I & 5 & 18 & 19 & 133 & 1.835 & 0.623 & 0.322 & 3.681 \\
II & 4 & 16 & 18 & 290 & 1.701 & 0.589 & 0.341 & 2.998 \\
III & 5 & 36 & 49 & 973 & 3.026 & 0.778 & 0.085 & 6.976 \\
IV & 3 & 6 & 7 & 50 & 1.185 & 0.609 & 0.462 & 1.534 \\
V & 4 & 9 & 10 & 71 & 1.500 & 0.651 & 0.324 & 2.111 \\
VI & 4 & 25 & 31 & 270 & 2.732 & 0.796 & 0.124 & 5.359 \\
VII & 5 & 32 & 45 & 503 & 3.222 & 0.846 & 0.059 & 7.073 \\
合计 Total & 5 & 42 & 63 & 2,290 & & & &
\end{tabular}

I: 典型草原; II: 湿地; III: 山地沟谷草甸; IV: 退化草原; V: 农田; VI：山地旱生灌丛; VII: 山地中生灌丛。

I, Typical grassland; II, Wetland; III, Mountain valley meadow; IV, Degraded grassland; V, Farmland; VI, Mountain xerophytic shrub; VII, Mountainous shrub. 

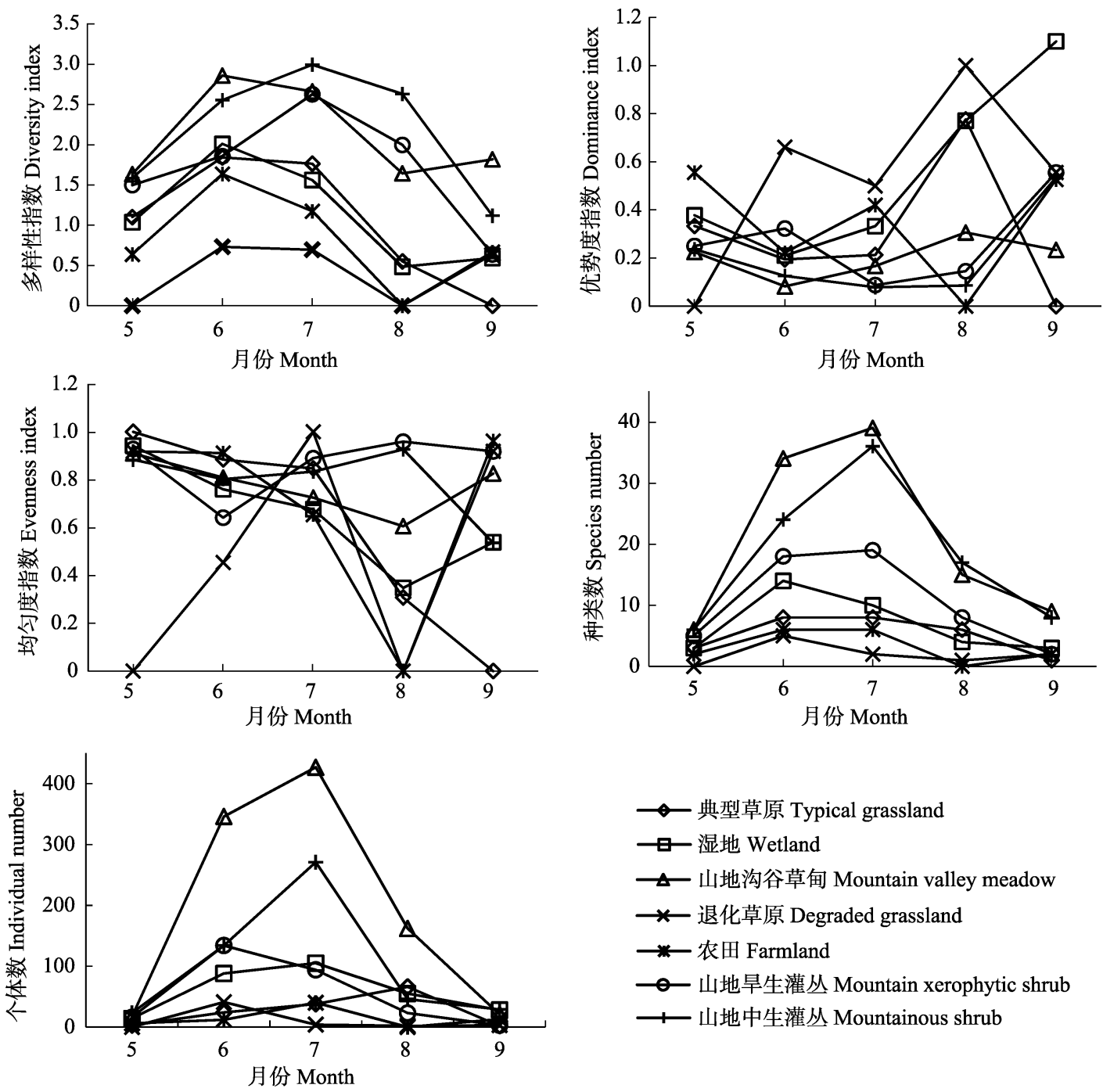

图4 不同生境蝶类群落的多样性指数 $\left(H^{\prime}\right)$ 、均匀度指数 $(J)$ 、优势度指数 $(D)$ 、个体数 $(N)$ 和种类数 $(S)$ 的时序动态

Fig.4 Temporal dynamics of the diversity index, evenness index, dominance index, individual number and species number of butterfly community in different habitat

降低; 湿地、山地沟谷草甸和农田生境在5-7月较为 平稳, 8月明显下降, 9 月又升高, 推测是由于 9 月降 水逐渐减少, 蛱蝶及粉蝶数量回升, 使均匀度升高; 山地旱生灌从和山地中生灌从在调查期内无较大 波动, 在8月达到最大值后逐渐降低。

优势度指数表现为: 湿地、山地旱生灌丛、山 地中生灌从都在 9 月达到最高值, 推测是由于 9 月气 温降低、寄主植物减少, 蝶类种类和数量减少, 导 致优势度升高; 典型草原、山地沟谷草甸、退化草 原的优势度在8月达到最大值。8月因受降雨影响生 境破坏较大, 草木萧疏, 典型草原中仅粉蝶科分 布、山地沟谷草甸中蝶类种类及数量大幅减少、退 化草原仅灰蝶科少数种存在。农田生境的优势度指
数波动较大, 5 月为最高值, 8 月为最低值, 可能是 8 月农作物在雨水滋润下生长旺盛, 为喜食十字花科 的蝶类提供食物和生存空间, 因而优势度最低, 5月 生存条件差仅有粉蝶科少数种分布, 优势度最高。

各生境个体数与种类数随月份变化呈现相同 规律, 退化草原和山地旱生灌从的个体数在6月达 到最大值, 其余样线最大值在7月, 之后逐渐减少。 湿地和退化草原的种类数在 6 月达到最大值, 其余 生境在7月达到最大值, 之后逐渐减少。这是由于 6-7月温度适宜, 寄主植物、蜜源植物等生长茂密, 凤蝶科、粉蝶科、蛱蝶科等处于高发期，此时蝶类 在种类和数量上都处于高产时期, 而8月开始多种 蝶类进入发生末期, 仅蛱蝶科、粉蝶科分布, 蝶类 
分布表现出明显的季节性。

\section{5 蝶类多样性与温湿度的相关性分析}

赛罕乌拉保护区最高气温出现在7月, 而降水 期主要集中在7-8月(图5), 5月冰雪消融并有少量降 水, 6 月降水少、气温高, 出现较短炎热干旱期。 Pearson相关性分析结果表明(表3), 月平均温度与 蝴蝶种类数和个体数呈显著正相关 $(P=0.885, P=$ $0.928)$, 是影响蝶类种类和数量的主要因子。6、7月 的平均温度分别为 $27.4^{\circ} \mathrm{C}$ 和 $30.9^{\circ} \mathrm{C}$, 适宜的温度使 蝶类种类和个体数均增多。降雨量与蝴蝶种类和个 体数无显著相关性, 7、8月份降水增多, 破坏生境资 源, 降低了蝴蝶的种类和数量。6月蝴蝶种类数达到 最大值(50), 个体数是在7月最多(979)。月平均温度 与月降水量无显著相关性。
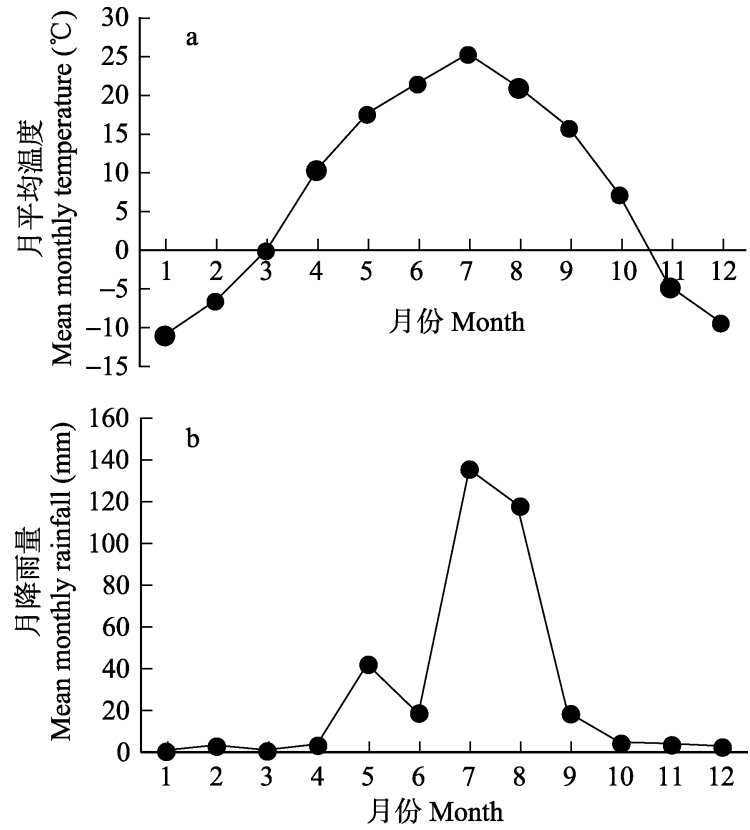

图5 赛罕乌拉保护区月平均温度(a)和月降雨量(b)

Fig. 5 Mean monthly temperature (a) and rainfall (b) at Saihanwula Nature Reserve

\section{3 讨论}

7种生境中, 具有适当干扰活动的山地沟谷草 甸中蝴蝶的科、属、种、个体数均最高, 可能是因 为适当的干扰活动可以帮助植物传粉、受精，有利 于植物种群的扩大, 从而增加蝶类寄主植物的丰富 度，更利于蝶类多样性发展。几乎无人为干扰的山 地中生灌从，阔叶和针叶的高大乔木占据优势生态 位，植被郁闭度较大，导致低矮灌木和草本植物减 少，植被垂直分布不均匀，蝶类繁殖和栖息受到影 响, 数量减少。研究结果符合在八仙山(胡冰冰等, 2010)、甘肃兴隆山(尚素琴等，2017)、宁夏云雾山 典型草原(陈芙蓉等，2013)中均证实过的中度干扰 假说。退化草原因放牧土壤沙化，植物生长受到限 制，仅有小叶锦鸡儿一种植被，蝶类生存繁殖受到 威胁, 种类及数量严重减少, 多样性指数和物种丰 富度指数均为最低, 科、属、种、个体数都是最少, 优势度指数最高。农田是由靠近河流的草场垦草造 田形成, 蝴蝶种类也主要集中在喜食十字花科的种 类，如云粉蝶等。典型草原、退化草原、农田生境 蝶类群落的种-多度曲线都表现为对数级数模型, 这3种生境的人为干扰程度都为中至强烈，生境破 坏较严重, 蝶类寄主植物较少, 主要为农作物及人 工林，所以蝶类以喜食十字花科植物的粉蝶类和以 杨柳为寄主的蛱蝶类为主。

蝶类体温随外界温度的变化而改变, 温度升高 可缩短蝴蝶幼虫和蛹的成熟时间，使羽化提前，温 度降低则会延长蝶类发育历期和滞育时段、降低蝴 蝶飞行速度和生长速度等(Jia et al, 2010; 李密, 2010)。保护区6-7月温度适宜，寄主植物丰富、蜜 源植物较多，为蝶类的取食、栖息、躲避天敌、飞 行、产卵等提供了良好的场所，是一年中蝶类生存 环境最佳的时段。各生境蝶类群落多样性指数、种

表3 气候因素与蝶类种类与个体数的Pearson相关性分析

Table 3 Correlation (Pearson's) between climatic factors and butterfly species and individuals

\begin{tabular}{lllll} 
& $\begin{array}{l}\text { 种类数 } \\
\text { Species number }\end{array}$ & $\begin{array}{l}\text { 个体数 } \\
\text { Individual number }\end{array}$ & $\begin{array}{l}\text { 月平均温度 } \\
\text { Mean monthly temperature }\end{array}$ & $\begin{array}{c}\text { 月降雨量 } \\
\text { Mean monthly rainfall }\end{array}$ \\
\hline 种类数 Species number & 1 & $0.981^{* *}$ & $0.885^{*}$ & 0.371 \\
个体数 Individual number & & 1 & $0.928^{*}$ & 0.460 \\
月平均温度 Mean monthly temperature & & & 1 & 0.732 \\
月降雨量 Mean monthly rainfall & & & 1 \\
\hline
\end{tabular}

${ }^{*} P<0.05 ;{ }^{* *} P<0.01$ 
类数、个体数在 $6-7$ 月达到最高值。许多研究表明 降雨量与蝶类种类和个体数呈负相关, 降雨影响蝶 类食物和生境, 且雨水会冲走部分在土壤浅层及枯 枝落叶层的幼虫和蛹, 增加死亡率, 降低蝴蝶的种 类和数量(贾玉珍等, 2010; Jia, 2010)。但本研究显示 蝶类种类和个体数与降雨无相关性, 可能与调查选 择晴朗天气，观测时间为全天气温相对较高、蝶类 活动频繁的时段有关，有待进一步深入研究。

综上所述，赛罕乌拉保护区整体生境较稳定， 适宜蝶类生存繁殖, 但退化草原、农田、湿地等由 于干扰较强烈, 环境质量遭到破坏, 植被物种丰富 度下降, 蝶类及其他物种多样性也降低。建议保护 区适当减少人为干扰以恢复生境, 保护蝶类群落多 样性。

致谢: 感谢全国蝴蝶观测成员在标本鉴定中提供的 帮助; 感谢赛罕乌拉自然保护区工作人员及当地居 民的支持与配合。

\section{参考文献}

Chen FR, Cheng JM, Liu W, Zhu RB, Yang XM, Zhao XY, Su JS (2013) Effects of different disturbances on diversity and biomass of communities in the typical steppe of loess region. Acta Ecologica Sinica, 33, 2856-2866. (in Chinese with English abstract) [陈芙蓉, 程积民, 刘伟, 朱仁斌, 杨 晓梅, 赵新宇, 苏纪帅 (2013) 不同干扰对黄土区典型草 原物种多样性和生物量的影响. 生态学报, 33, 2856-2866.]

Chen L, Feng J, Liu XL, Li F, Xie SL (2013) Characteristics of algae flora and community in Saihanwula Nature Reserve, Inner Mongolia. Acta Hydrobiologica Sinica, 37, 376-382. (in Chinese with English abstract) [陈乐, 冯佳, 刘晓铃, 李峰, 谢树莲 (2013) 赛罕乌拉自然保护区藻类植物区 系及群落结构特征. 水生生物学报, 37, 376-382.]

Fang LJ, Xu HG, Guan JL (2013) History and present status of butterfly monitoring in Europe and related development strategies for China. Chinese Journal of Applied Ecology, 24, 2691-2698. (in Chinese with English abstract) [房丽君, 徐海根, 关建玲 (2013) 欧洲蝴蝶监测的历史、现状与我 国的发展对策. 应用生态学报, 24, 2691-2698.]

Gu W, Ma L, Liu ZQ, Jiao Y, Wang LD, Zhang C, Sun H, Sun MO (2015) Diversity of butterflies in Liangshui Nature Reserve of Xiao Xing'an Mountains. Acta Ecologica Sinica, 35, 7387-7396. (in Chinese with English abstract) [顾伟, 马玲, 刘哲强, 焦玥, 王利东, 张琛, 孙虎, 孙美欧 (2015) 小兴安岭凉水自然保护区蝶类多样性. 生态学报, 35, 7387-7396.]
Ha Q, Wang MJ, Chang GJ, Chen HJ, Shan YM, Huang F (2013) The vegetation carbon density and distribution of different grassland patterns in Saihanwula National Nature Reserve. Journal of Arid Land Resources and Environment, 27(4), 41-46. (in Chinese with English abstract) [哈琴, 王 明玖, 常国军, 陈海军, 单玉梅, 黄帆 (2013) 赛罕乌拉 国家级自然保护区不同草地类型植被碳密度及其分配. 干旱区资源与环境, 27(4), 41-46.]

Hu BB, Li HH, Liang ZP, Zhao TJ, Ren XB (2010) Diversity and fauna of butterflies in Baxian Mountain State Nature Reserves. Acta Ecologica Sinica, 30, 3226-3238. (in Chinese with English abstract) [胡冰冰, 李后魂, 梁之聘, 赵 铁建, 任秀柏 (2010) 八仙山自然保护区蝴蝶群落多样 性及区系组成. 生态学报, 30, 3226-3238.]

Jia XY, Wang XJ, Niu JM, Zhang WJ, Liu YJ (2014) Water conservation services of different vegetation types in the Saihan-Ulla National Nature Reserve. Arid Zone Research, 31, 495-501. (in Chinese with English abstract) [贾晓燕, 王晓江, 牛建明, 张文军, 刘玉军 (2014) 赛罕乌拉国家 级自然保护区不同植被类型水源涵养服务特征. 干旱区 研究, 31, 495-501.]

Jia YZ (2010) Study on Quantitative Dynamics of Insect along Successional Gradient in Broad-leaved and Korean Pine Mixed Forests in the Changbai Mountain, China. PhD dissertation, Beijing Forestry University, Beijing. (in Chinese with English abstract) [贾玉珍 (2010) 长白山阔叶红松林 不同演替阶段昆虫数量动态研究. 博士学位论文, 北京 林业大学, 北京.]

Jia YZ, Zhao XH, Meng QF (2010) Effects of temperature and rainfall on composition and diversity of butterfly in broad-leaved and Korean pine mixed forest in the Changbai Mountains, China. Chinese Journal of Applied and Environmental Biology, 16, 7-12.

Li JL, Pei HY, Liu DJ, Yang HS, Zhang YQ, Luo ZW (2011) Diversity of butterfly species in different habitats in Shenjiadian Forest Areas. Journal of Environmental Entomology, 33, 308-314. (in Chinese with English abstract) [李佳琳, 裴海英, 刘德江, 杨洪升, 张雨奇, 罗志文 (2011) 申家 店林区不同生境蝶类多样性调查. 环境昆虫学报, 33, 308-314.]

Li M (2011) Studies on Conservation Biology of Butterfly in Wuyunjie National Nature Reserve. PhD dissertation, Hunan Agricultural University, Changsha. (in Chinese with English abstract) [李密 (2011) 乌云界国家级自然保护区蝴蝶保 护生物学研究. 博士学位论文, 湖南农业大学, 长沙.]

Li ZG, Yin W, Zhong W, Xiong JW, Hu HY (2017) An investigation of butterfly resources in mountain steppe of Xarxili Nature Reserve, Xinjiang. Journal of Xinjiang University (Natural Science Edition), 34, 218-222. (in Chinese with English abstract) [李照广, 尹弯, 钟问, 熊嘉武, 胡红英 (2017) 新疆夏尔希里自然保护区山地草原带蝴蝶资源调 查. 新疆大学学报(自然科学版), 34, 218-222.]

Liu LW, Pan CC, Liu JL, He L (2015) Resources and fauna of 
butterflies in Jiulongshan Mountain National Nature Reserve. Chinese Journal of Ecology, 34, 3438-3442. (in Chinese with English abstract) [刘立伟, 潘成椿, 刘菊莲, 何 亮 (2015) 九龙山国家级自然保护区蝶类资源与区系. 生态学杂志, 34, 3438-3442.]

Mei J, Ran H, Yang TY, Xu QZ (2015) Species diversity of butterflies in Fanjing Mountain National Nature Reserve of Guizhou. Chinese Journal of Ecology, 34, 504-509. (in Chinese with English abstract) [梅杰, 再辉, 杨天友, 许勤 智 (2015) 贵州梵净山国家级自然保护区蝴蝶多样性. 生态学杂志, 34, 504-509.]

Shang SQ, Zhang HY, Tian FB, Ru Y, Zhou HL (2017) Diversity of butterfly fauna in Xinglongshan National Nature Reserve of Gansu Province. Pratacultural Science, 34, 1314-1322. (in Chinese with English abstract) [尚素琴, 张 红勇, 田赋斌, 汝阳, 周惠丽 (2017) 甘肃省兴隆山国家 级自然保护区蝶类区系组成与多样性. 草业科学, 34, 1314-1322.]

Tan C, Wang TY, Wang L, Fan DM, Ma J, Liu CH (2017) Butterfly diversity of different interference habitats in Nanniwan wetland. Chinese Journal of Ecology, 36, 2840-2846. (in Chinese with English abstract) [谭灿, 王亭贻, 王璐, 禁德苗, 马娟, 刘长海 (2017) 南泥湾不同干扰湿地蝶类 多样性. 生态学杂志, 36, 2840-2846.]

Weng JQ, Lü WL, Hu SJ, Zheng JH, Li ZG (2017) Butterfly species diversity in Gutian Provincial Nature Reserve, Guangdong. Chinese Journal of Ecology, 36, 132-136. (in Chinese with English abstract) [翁锦洇, 吕文龙, 胡诗佳, 郑基焕, 李志刚 (2017) 广东古田自然保护区蝶类群落 多样性. 生态学杂志, 36, 132-136.]

Wu YH, Gu ZR, Liao CL, Wang XY, Gu Q, Xiang Y (2016) Research progress of butterflies diversity in the Badagongshan National Nature Reserve. Study on Insect in Central
China, 12, 124-128. (in Chinese with English abstract) [吴 雨恒, 谷志容, 廖春林, 王秀英, 谷祺, 向阳 (2016) 八 大公山国家级自然保护区蝴蝶多样性研究进展. 华中昆 虫研究, 12, 124-128.]

Zhang LW, Zhang HY (2016) Research progress in butterfly as indicators for habitat change. Journal of Biology, 33(3), 88-91. (in Chinese with English abstract) [张立微, 张红玉 (2016) 蝶类对生境的指示作用研究进展. 生物学杂志, 33(3), 88-91.]

Zhang SL, Yong WY, Yang YX, Lu ZX, Zhang F, Li GL (2008) Study on the vegetation classification in Saihanwula Nature Reserve. Journal of Inner Mongolia University (Natural Science Edition), 39, 74-79. (in Chinese with English abstract) [张书理, 雍伟义, 杨永所, 卢朝霞, 张帆, 李桂林 (2008) 赛罕乌拉自然保护区植被分类研究. 内 蒙古大学学报(自然科学版), 39, 74-79.]

Zhou GY, Gu MB, Gong YN, Wang SK, Wu ZM, Xie GG (2016) Diversity and fauna of butterflies in Nanling National Nature Reserve. Journal of Environmental Entomology, 38, 971-978. (in Chinese with English abstract) [周光益, 顾茂 涁, 龚粤宁, 王胜坤, 吴仲民, 谢国光 (2016) 南岭国家 级自然保护区蝴蝶多样性与区系研究. 环境昆虫学报, 38, 971-978.]

Zhou Y (1994) Monographia Rhopalocerorum Sinensium. Henan Science and Technology Press, Zhengzhou. (in Chinese) [周尧 (1994) 中国蝶类志. 河南科学技术出版社, 郑州.]

Zhou Y (1998) Classification and Identification of Chinese Butterflies. Henan Science and Technology Publishing House, Zhengzhou. (in Chinese) [周尧 (1998) 中国蝴蝶分 类与鉴定. 河南科学技术出版社, 郑州.]

(责任编委: 黄晓磊 责任编辑: 问文杰) 